\title{
Breast Cancer, A Stem Cell Disease
}

Rogelio González-Sarmiento (1) (2) and Jesús Pérez-Losada (1) (*)

(1) Departmento de Medicina (Facultad de Medicina). Universidad de Salamanca. Salamanca. Spain.

(2) Centro de Investigación del Cáncer. Universidad de Salamanca/CSIC. Salamanca. Spain.

$\left(^{*}\right)$ Address correspondence to this author at the Universidad de Salamanca

Campus Miguel de Unamuno s/n. Salamanca, 37007. Spain

Phone: 34-923-294553

FAX 34-923-294593

Email: jperezlosada@usal.es

Keywords: Stem cell, breast cancer, self-renewal, hierarchy, progenitor. 


\begin{abstract}
Breast cancer is a first magnitude problem of public health worldwide. There is increasing evidence that this cancer is originated in and maintained by a small population of undifferentiated cells with self-renewal properties. This small population generates a more differentiated pool of cells which represents the main mass of the tumor, resembling the hierarchical tissue organization of the normal breast. These cancer stem cells seem to share a similar phenotype with their normal counterparts but they display dysfunctional patterns of proliferation and differentiation, and they no longer respond to normal physiological controls that ensure a balanced cellular turnover. The origin of these cancer stem cells is controversial; it is not well known if they are originated from normal stem cells or from more differentiated progenitors where a de novo stem cell program is activated by the oncogenic insult. Here we review the origin of breast cancer stem cells and their role in the pathogenesis of cancer development, together with their implications in breast cancer progression, treatment and prognosis.
\end{abstract}




\section{INTRODUCTION}

The hierarchical tissue organization of cellular replacement by stem cells was originally described in 1965 by Gilbert and Lajtha in the hematopoietic system [1]; this concept has been later extrapolated to other tissues including breast [2-4]. In the last few years, the characterization of stem cells in different organs supports the hypothesis that all tissues have stem cells and, to some degree, a hierarchical organization [5]. The term stem cell defines cells with self-renewal potency and the ability to give rise to multiple lineages; in normal adult tissues stem cells are responsible for generating and maintaining the tissue architecture and for ensuring a balanced cellular turnover. The equilibrium between cell renewal and cell loss is carefully controlled by communications between tissue stem cells and the microenvironment to permit precise responses to stresses caused by tissue damage or to control normal tissue remodeling [6]. Mammary gland is a very dynamic organ, with big fluctuations in cell proliferation in every menstrual cycle and also undergoes enormous developmental changes during pregnancy, lactation and involution. These processes are properly controlled by systemic hormones and by local epithelialstromal interactions [7], and suggest the existence of stem cells able to generate new lobules during mammary remodeling. In 1959, DeOme and collaborators observed that the parenchyma isolated from different regions of the breast was able to generate mammary tissue outgrowths containing different cell lineages of the mammary gland and proposed the existence of mammary stem cells [8]. Earlier studies by Pierce and collaborators suggested that not only normal cell lineages of the mammary gland, but also breast cancer would have the origin in and be maintained by stem cells (cancer stem cells) [9-11]. It seems clear that breast cancer is developed after decades of the oncogenic initiation $[12,13]$ and, due to the high cellular turnover of the mammary gland, stem cells would be the only subpopulation present in the tissue enough time which provide to accumulate all the oncogenic alterations needed to generate cancer [14-19]. There is a question of controversy if these cancer stem cells would have the origin in their normal counterparts or the oncogenic insult would induce a stem cell-like program in a more differentiated progenitor [6].

In this article we summarize the current information about normal mammary stem cells, breast cancer hierarchy, and mammary cancer stem cells. We also discuss the 
implications of cancer stem cell hypothesis in cancer initiation and tumor cell fate, and its clinical consequences in dissemination, relapse, treatment and susceptibility. Lastly, we shortly summarize the molecular pathways related with stem cell self-renewal capacity.

\section{NORMAL BREAST STEM CELLS}

The epithelial component of the mammary tissue is composed by different cell lineages including ductal, alveolar and myoepithelial cells. In parallel with other organs, mainly the hematopoietic tissue, it was suggested that all these glandular cells could have their origin in the same cell progenitor with self-renewal capability, indicating there would be a hierarchical tissue organization in the mammary gland (Fig. 1). This idea was supported by several pieces of evidence. Firstly, the physiological characteristics of the mammary gland itself, with high remodeling capacity necessary for its continuous cycles of involution and redevelopment, indicate the requirement of stem cells to permit this high cellular turnover. Secondly, there is the fact that entire lobules of the gland sometimes contain identical X-chromosome inactivation in all cells, independently of the cell lineage, indicating their clonal origin [20]. This is similar to what is demonstrated in mammary tumors which can also be composed from different cell types, but all of them share similar chromosomal aberrations indicating a clonal origin too [21, 22]. Lastly, small portion of the developing tissue or even the lactating organ can generate a complete mammary gland with the entire branching tree. All these data together, suggest the clonal origin of the epithelial cells of the mammary gland and the existence of stem cells. This idea was strongly supported by the elegant work done by Kordon and Smith who demonstrated that a single retrovirally marked epithelial cell can reconstitute the whole mammary gland [2], and this was further later confirmed later on by two recent works demonstrating that the entire mammary gland can be regenerated by the progeny of a single stem cell with well-defined cell surface markers [3, 4]. 


\section{Identification of Mammary Stem Cells}

The data suggesting the existence of mammary stem cells lead to develop a number of approaches to isolate and identify these cells. An interesting strategy to recognize mammary stem cells is based on the defined characteristic that stem cells are mostly quiescent and infrequently divides, for this reason retain labeled DNA precursors like bromodeoxyuridine [23-25]; thus stem cells are included in the pool known as Label Retaining Cells (LRCs). This strategy has permitted the use of these population rich in putative stem cells to analyze markers that define the stem cell compartment. In this regard, it has been demonstrated that LRCs express P21 and Mushashi-1 which have been previously considered as stem cell markers [26]. A similar strategy with H3-thymidine permitted Pierce and collaborators in the 70's, demonstrated the existence of LRCs in tumors and proposed the existence of putative breast cancer stem cells [10, 11].

Other strategy to identify stem cells is based on their ability to exclude dyes such as Hoechst, feature owed to the expression of a family of membrane transporters [27, 28]. When the cells are analyzed by flow cytometry they can be identified as the side population (SP), similar to that demonstrated in the hematopoietic system [28-30]. Interestingly, SP cells sorted from the mouse breast can regenerate the mammary gland after transplantation [29, 31] and have also been identified in the human mammary gland [26, 29, 32-34]. An important portion of SP cells loss linage specific markers [26], has the capability to generate myoepithelial and luminal cells (Fig. 1) and form branching structures in matrigel with both cell lineages [26, 32, 34]. These cells also expressed previously identified putative stem cells markers, such as P21 and Mushashi-1, and were mainly ER-alpha positive [26].

The use of putative surface stem cell markers and flow cytometry to identify populations with bipotent differentiation capability [26, 35-37] has been also useful in the identification of possible stem cells populations. These bipotent progenitors were described as ESA (Epithelial Specific Antigen) positive, MUC-1 (mucin-1) positive and CALLA negative, and were able to generate ductal-acinar structures [34, 37]. Other multiple surface and inner cell markers have been proposed for the identification of human stem cells including P21 and Mushashi-1 [26]; Cytokeratins 5/6 and 19 [37, 38]; CD49f [36]; EpCAM [37], and Bmi-1 [39]. In the mouse, both Sca-1 and telomerase has 
been proposed as stem cell makers [24, 29]. More recently, it has been isolated a population of cells, defined as Lin-CD29hiCD24+, with self-renewal capacity and the ability to regenerate the complete mammary gland [3, 4] (Fig. 1).

An interesting assay to identify mammary stem cells is based on the parallelistic behavior that breast stem cells share with neural stem cells. Undifferentiated multipotent progenitors of neural cells can grow in suspension as neurospheres that are rich in stem cells $[40,41]$. The same conduct has been demonstrated in cells from the mammary gland that grow in suspension under serum-free conditions and in the presence of some growth factors to form the so-called mammospheres [32, 39, 42]. Interestingly, only SP cells are capable to form mammospheres which in turn are enriched in $27 \%$ of SP cells [32]. The second generation of mammospheres probably lost stem cells properties, since they express progenitor markers like CALLA, $\alpha 6$-integrin and only half of the spheres contains EpCAM (epithelial cell adhesion molecule) positive cells, a putative stem cell marker [37].

\section{Location of Mammary Stem Cells}

An important question to explain is where the stem cells are located within the mammary gland. It has been proposed that stem cells are generally positioned in a place called the stem cell niche, a specialized spot whose task would be to supply stem cells with the proper environment to permit their function correctly $[5,6]$. Breast stem cells by definition, cannot be committed to any cell lineage, so they should not express any differentiation-specific markers. This idea was used in an attempt to localize the mammary stem cell niche. In this regard, a population of undifferentiated cells that lack the expression of linage-specific markers was located around the terminal end-buds (TEB) during the branching ducts, known as cap cells. These cells have been considered as candidates for mammary stem cells and are present in both human and mice [43-46]. Interestingly, they disappear when the branching process is completed, but the stem cell potentiality is not lost and can be manifested again in a next pregnancy. This fact suggests other than the cap cells should maintain a dormant stem cell capacity under these conditions $[8,47,48]$. Electronic microscope studies in the mouse indicated the stem cell function could still be present in the luminal compartment, in the denominated 
small light cells [49], that probably are equivalent to the human basal clear cells located a the tip of the alveoli by the optic microscope, but it is not clear if these are real stem cells, or only myoepithelial cells precursors [50]. In any case, there is increasing evidence indicating that mammary stem cells would be located in the luminal compartment; this fixes well with the idea that myoepithelial cells are terminal differentiated and very difficult to be transformed [51]; but during the physiological remodeling processes, mammary stem cell activity can be also localized at the terminal ducts [52]. This stem cells would be keratin-5 positive, ESA positive and MUC-1 negative (luminal marker of terminally differentiated cells), and they would later acquire markers of terminal differentiation, establishing a cell hierarchy in the mammary gland [53] (Fig. 1).

\section{Stem Cell Hierarchy and Cell Fate Decision}

Due to the essential role of estrogen in the mammary gland development and remodeling together with its importance in breast cancer growth and treatment, it is of essential importance to know how the cell hierarchy in the mammary gland is organized and its relationship with estrogens responses. The location of estrogen receptor (ER) positive cells in the mammary gland has been a matter of controversy; an interesting scheme of stem cell hierarchy regarding the ER receptor has been proposed by Dontu and coauthors [54], who propose the existence of most primitive long-term ER negative stem cells capable of regenerating a complete mammary gland [2], they would be equivalent to the recently identified mammary repopulating units Lin-CD29hiCD24+ and CD49f+ $[3,4]$ (Fig. 1). These cells would lead to the short-term ER positive stem cells capable to generate colonies in vitro and patches of mammary epithelium during the adult tissue remodeling [20] (Fig. 1). This population would generate the ER negative transit amplifying cells that ultimately differentiate to myoepithelial and luminal lineages, defined by specific cluster of keratins and markers. Luminal lineage has been defined as keratins 7, 8, 18 and 19 positive and ESA+, CALLA +, MUC +; and myoepithelial lineage has been identified as keratins 5, 14, 17 positive and smooth muscle actin (SMA) positive (Fig. 1). Whereas luminal lineage is determined by the transcription factor GATA-3 which in turn induces FOXA1, it is not known what the molecular pathway is 
which determines myoepithelial cell fate decision. FOXA1 is essential to collaborate with $\mathrm{ER} \alpha$ in the activation of estrogen pathway-dependable genes [55, 56].

\section{BREAST CANCER STEM CELLS}

There is increasing evidence that stem cells are not only the origin of normal tissues, but also the origin of cancer. Tumors would be structured in a cell-hierarchy similar to that found in their normal tissue counterparts, resembling, as Pierce suggested, caricatures of tissue renewal [9]. Thus cancers would have their own stem cells (cancer stem cells), to permit the immortalization of the tumor tissue. The existence of breast cancer stem cells was proposed by Pierce and collaborators in the 70's [10, 11] and a lot of pieces of evidence have been built up till then. Epidemiological data from populations under radiation exposure suggest that breast cancer develops after decades of the oncogenic initiation $[12,13]$ and stem cells are the only population that live long enough to accumulate all the oncogenic alterations needed to generate breast cancer [14-19]. The existence of breast cancer stem cells implies both biological and clinical consequences.

\section{Biological Implications}

A complete understanding of the cancer process requires much more detailed knowledge of the tumor tissue organization and the origins of neoplastic growth, this means to know when the initiated cells begin to show altered behavior. It is therefore necessary to identify the initial target cell and its respective contributions to tumor fate determination and disruption of local homeostasis. The identification of cancer stem cells has a number of biological implications that permits to have a more comprehensive scenario of breast cancer.

\section{Cell Hierarchy in Breast Cancer}

Tumor tissues have been described by Dvorak as "wounds that do not heal” [57], since they no longer respond to normal physiological controls and grow indefinitely. Selfrenewal activity must be present in tumors to permit their progressive growth. However, it was not clear if this property was present in all cancer cells or, like normal tissues, cancers also have a hierarchical architecture in which only a subpopulation of cells has 
self-renewal capacity. Early studies, in both leukemias and solid tumors, demonstrated that only a small number of cancer cells have clonogenic potential and are responsible for the maintenance of the tumor and the progressive malignant growth [5, 6, 58-62]. This was also demonstrated in breast cancer where it was confirmed that not every single cell in the tumor has self-renewal properties, instead only a small population of cells was capable enough to form tumors when transplanted into immunocompromised NOD-SCID mice [63]. These breast cancer stem cells were identified as ESA+, CD44+, CD24low and they lack specific lineage markers. Recently, breast cancer propagating cells have been isolated and spread in vitro, proliferate extensively in non-adherent mammospheres, and interestingly, they still keep some differentiation capacity as they generate both myoepithelial and luminal lineages [64]. In summary, the data above indicated the existence of a cell hierarchy inside the breast tumors and the existence of breast cancer stem cells, but the origin of this cell subpopulation is controversial.

\section{Breast Cancer Stem Cell Origin}

The existence of a hierarchy in breast cancer as in the mammary tissue, arise the question of cancer-initiating cells. The self-renewal capacity should be originally present in the cancer-initiating cells, but it is a question of debate if this is an inner property of the initially transformed cell or the oncogenic event activates a stem cell-like program in a more differentiated progenitor without self-renewal potential [6]. Although the most logical interpretation could be the consideration of normal stem cells as the cancer initiating-cells due to its long life and the possibility to accumulate all the necessary oncogenic events to be transformed, it has also been indicated that a progenitor cell may become a cancer stem cell by acquiring a self-renewal program in different leukemia models [65-67] (Fig. 1). In case of breast cancer, mouse models also offer controversial results, for example, MMTV-Wnt1 transgenic mice display an expansion of a breast cancer stem cell population since they are enriched in CD29hi, CD24+, Sca1+ and keratin-6 [3, 23], whereas $M M T V-c N e u$ and $H$-Ras have a significant reduction in this population; for this reason, it has been suggested that the target cells in MMTV-Wnt1 mice would be a more primitive stem cell than in the other models. In a similar way, in human breast cancer, it has been proposed that the existence of two different 
subpopulations of cancer stem cells; the most primitive one would be the long-term repopulating ER $\alpha$ negative stem cell, which might generate $\mathrm{ER} \alpha$ negative breast cancer stem cells and originate ER $\alpha$ negative tumors; whereas short-term repopulating ER $\alpha$ positive stem cells might generate ER $\alpha$ positive breast cancer stem cells that would lead to ER $\alpha$ positive tumors [54]. This might indicate that the ER $\alpha$ status of the tumor would be determined by the ER $\alpha$ condition of the target cell; but this hypothesis can not explain the existence of both kinds of cells in breast tumors. In a broader scenario, this discussion raises the question of what determines tumor cell fate.

\section{Breast Cancer Cell Fate}

It is not clear what determines the final breast cancer phenotype; it is possible that this might be determined by the grade of differentiation of the target cell where the oncogenic event takes place [54]. Another possibility might be that different tumor phenotypes arise from the same most primitive target stem cell which could develop partial differentiation induced by a particular combination of oncogenic events. The incomplete state of differentiation acquired by the cell population generated by those cancer stem cells might be reflected in the final tumor phenotype (Fig. 1). An intermediated hypothesis proposes the possible existence of a continuum of stem cells with higher to lower possibility to be transformed that might explain the existence of different tumor phenotypes [6, 54].

The best defined phenotypes of breast cancer by expression profiles are the luminal and the basal-like tumors. Luminal tumors are mainly ER-positive with or without progesterone receptor (PR) and are GATA-3 positive. Basal-like tumors are defined by the expression of cytokeratins 5, 14 and 17 and a lack of ER, PR and GATA-3 expression. Actually, there is a bunch of mouse models that share features with human tumors, including luminal (MMTV-Pymt, MMTV-Neu, Wap-Int, Wap-cMyc) and basal (Brca-1 deficient models, Wap-Tag, C3(1)-Tag) [68]; but these promoters tag different subpopulations of cells making difficult to elucidate which is the cell of cancer origin. The development of new mouse models of breast cancer with the possibility to express the oncogenic events in specific cellular subpopulations within the tissue, and the expression of specific oncogenic events in the same population, will provide new tools for the resolution of these controversial questions. 


\section{Clinical Implications}

Regardless of whether the target cell for cancer development is a stem cell or one of its more differentiated progeny that acquire a stem cell-like program, the final consequence will be the same, only a small population of cells with self-renewal capability is essential for tumor maintenance [5, 6, 58-63]. The fact that only a small population of tumoral cells has self-renewal properties has very important clinical consequences. There is increasing evidence that this population is crucial not only for cancer maintenance, but also for cancer progression, dissemination, treatment response, and tumor relapse (Fig. 2).

\section{Metastasis}

Cancer dissemination is the most dangerous stage in tumor evolution. If only a small population of cells is necessary to maintain the primary tumor tissue, the same applies for metastatic deposits at distant sites. Although tumors can shed millions of cells into the blood, few of them lead to secondary tumors [69], and metastatic growth will therefore only be achieved if the cell reaching the site has self-renewal and tumor-maintenance capacity. It has been proposed that under physiological conditions adult stem cells could move from one tissue to another through the blood vessels and contribute to general tissue architecture. Blau and collaborators called this dissemination pathway the "Stem Cell Highway" [70]; if this was correct, it seems likely that tumor cell metastasis would occur by the same normal process of stem cell spread. In other words, the behavior of metastatic cancer cells would mimic the biological properties of normal stem cells (Fig. 2).

\section{Cancer Therapy}

Actual cancer therapies are mainly against proliferative cells, if we assume that cancer stem cells could have a similar behavior than their normal counterparts, probably at least part of them might be quiescent and refracting to the standard therapies also due to the expression of proteins associated with the efflux of drugs that provide resistance to multiple chemotherapeutic agents [71-74]. If ER $\alpha$ positive tumors were maintained by a small population of ER $\alpha$ negative stem cells, mostly quiescent; this scenario could 
explain the relapse of these tumors after the treatment with hormonotherapy. To cure cancer, we must achieve a complete eradication of the cells with tumor-maintenance capacity. If just a single cancer stem cell is spared, the consequence could be recurrence within months or even years after the initial treatment. Additionally, cancer stem cells would be the tumor subpopulation that acquires the mutations responsible for the resistance to standard therapy. Thus one of the main challenges for the next future will be the development of new therapeutic strategies for the specific recognition and eradication of these cancer stem cells. One possibility would be to introduce therapy strategies that induce cancer stem cells differentiation. To understand those pathways implicated in selfrenewal potential, an asymmetric division will be an essential part to develop these new strategies of therapy.

\section{Tumor Dormancy and Cancer Relapse}

Cancer recurrence is one of the main problems to solve in clinical practice. Around $50 \%$ of women with apparent early-stage of breast cancer will develop metastatic disease after years of the initial remission. The reactivation of previously dormant cancer stem cells [75] could explain the long-term relapse that has been described in leukemias and solid tumors such as melanomas and breast cancer [76-80]. The factors that cause dormant cancer stem cells to become reactivated are not understood, but might be related to failure of the immune system [81] or angiogenesis [82]. Some light might arise from classical chemical carcinogenesis studies; two-stage carcinogenesis protocols involve initiation with a low dose of a mutagen such as DMBA (7,12-dymethylbenz[a]anthracene) and subsequent prolonged exposure to the tumor promoter TPA (12-O-tetradecanoyl phorphol-13-acetate). Mice treated with initiating doses of DMBA without subsequent promotion by TPA do not develop tumors. However, when promotion with TPA is started one year after the exposure to DMBA the tumor response is the same in terms of latency and yield, as if it was started one week after initiation. These seminal experiments arise important clues: First, these studies implicate a stem cell population as the main target for cancer initiation, as only stem cells live long enough to develop tumors after long period of time; secondly, exposure of the host to external or internal physiological promoter agents can reintroduce initiated long-term dormant cancer stem cells in cycle 
and originate or reinitiate the tumor. The same might apply for dormant cancer stem cells after the first round of treatment with chemotherapy, and the long-term tumor recurrence (Fig. 2). It would be important to understand the mechanisms by which stem cells and cancer stem cells abandon the cell cycle and are kept in check for such long periods of time as well as the process that leads to their reawakening.

\section{BREAST CANCER SUSCEPTIBILITY AND STEM CELLS}

The classical two-stage chemical carcinogen protocol to induce skin cancer in mice, offers an interesting parallelism with breast cancer development. After an application of a mutagen like DMBA and subsequent long term promotion with TPA, mice develop skin tumors. Indeed, it is well-known that the role of the estrogens as long-term promoter agents in breast cancer promotion along the women life; but an issue with essential implications is to know the exact moment when the initiation event takes place. Studies in populations from Hiroshima and Nagasaki that suffer high dose radiations showed that the girls who were between 10 and 14 years of age at the time of radiation exposure were the most susceptible population to develop a higher incidence of breast cancer, meaning that the puberal breast of young virgin women is very vulnerable to any carcinogenic exposure [12]. This behavior has also been demonstrated in mice where viral infection with the MMTV (Mouse Mammary Tumor Virus) later than 6 weeks of age after the onset of the estrus does not generate mammary tumors [83]. This could indicate that the period of maximum susceptibility to breast cancer initiation is early in life. Russo named the period of carcinogen susceptibility between the onset of puberty and first pregnancy “The Susceptibility Window” [84]. Unfortunately, the initiation agents, apart from radiation, in most cases are not known, but epidemiological studies in immigrant populations suggest that they seem to be related with multiple factors of the Western way of life [85].

It is well-documented that the protective effect is connected with the early first pregnancy in human breast cancer development, the shorter the period till the first pregnancy the lower will be the possibility to develop breast cancer [86, 87]. This 
concept has also been extended to viral and chemical carcinogenesis in mice and rats [84, 88-95]. Animals were shown to remain susceptible until their first litter and the nursing of their pups [84, 97, 98]. This important aspect of breast cancer behavior is not recapitulated by most of actual genetic engineering mice (GEM) that use promoters induced by estrogens, like the LTR from the MMTV or WAP [68] but, in other contexts, it has been also demonstrated that the consequences of aberrant $c M Y C$ activation in the mammary gland are determined by the developmental state of the gland at the time of cMYC exposure [98]. The protection effect of the early pregnancy has been attributed to the almost completed differentiation of the mammary gland at the time of the carcinogen administration [100]. Mammary carcinomas induced by DMBA to young virgin rats come up from the undifferentiated terminal ductal structures identified as TEB [84]. During pregnancy and lactation the complete development of the mammary gland is manifested by the terminal differentiation of the TEBs into alveolar ducts and lobules. This terminal differentiation of the gland would lead to resistance to carcinogens by parous mammals. In other words, the incomplete differentiation of the gland at the time of carcinogen administration makes it susceptible to develop breast cancer later in life. It is demonstrated that there is a change in the breast architecture after the first pregnancy, with an increase in cell proliferation and tubular branching. Russo and collaborators interpret this transformation as a switch from lobules type 1 and 2 to lobules type 3 and 4, where there is a progressive increase in branching and ductal complexity. These authors have proposed that breast structures after menopause, in both nulliparous and parous women, are again lobules type-1, but those from nulliparous women are susceptible to develop cancer. It has been suggested that this fact could be explained by the existence of two types of stem cells, type 1 stem cells would be present in type 1 lobules, and after pregnancy they would switch to type 2 stem cells which would be refractory to be transformed [100-102]. In fact, two possible types of mammary stem cells have also been proposed by other group, long-term repopulating ER negative stem cells and short-term ER positive stem cells [54] (Fig. 1). It would be very interesting to clarify if there is any association between these two concepts. In an attempt to identify the reason of this refractivity to cancer development, the gene expression signature of the parous mammary gland in rats and mice by expression arrays have been investigated [97, 103, 104]; 
demonstrating that TGF $\beta 3$ levels are upregulated, among others [97, 103]. It is not wellunderstood the process by which an early first pregnancy induces a refractory behavior of the mammary gland to cancer development; to know the precise mechanisms by which these mechanisms occur would be essential to develop strategies for breast cancer prevention.

\section{SIGNALING PATHWAYS INVOLVED IN MAMMARY STEM CELL RENEWAL}

Self-renewal is an essential condition that permits tissues to growth and be maintained in physiological conditions, like in tissue repair and remodeling; on the other hand, selfrenewing is a hallmark of cancer. The mechanisms that control cell-renewal in physiological and pathological processes seem to be the same, and the deregulation of these mechanisms lead to cancer development. Thus cancers could be considered as selfrenewal diseases. There are several signaling pathways that have been related with stem cell self-renewal in the mammary gland and have been implicated simultaneously in embryonic breast development, adult tissue remodeling, and breast cancer generation.

\section{Wht Pathway}

There is a number of data involving Wnt pathway with mammary stem cell self-renewal. Firstly, Wnt signaling has been implicated in mammary gland morphogenesis and development; in both early stages of the mammary gland embryogenesis and adult tissue remodeling during pregnancy and lactation. Several Wnt ligands are expressed differentially at different stages of the mammary gland development $[105,106]$, and deregulation of the pathway leads to gland structural defects, for example, Wnt-4 deficiency leads to a delay in side-branching [107]. Secondly, Wnt signaling pathway is active in more than 50\% of carcinomas [108]. The participation of Wnt pathway in breast cancer development seems to be complex, since some members of the pathway, for example Wnt-7, seem to be downregulated [109], whereas others, like Wnt-2, are overexpressed in breast cancer [110]. This ambivalent function also could have clinical 
implications since it has been described a possible suppressor effect in some components of the pathway; this would be the case of Wnt-5a whose loss leads to an increasing risk of relapse in ductal breast cancer whereas its presence has been indicated as a sign of good prognosis [111].

The deregulation of Wnt pathway not only delay the self-renewal program but also seems to block the differentiation process altering the gland morphogenesis; for example, the overexpression Wnt-1 or Wnt-10b in transgenic mice generate premature ductal branching and alveolar development leading to lobule-alveolar hyperplasias that eventually progress to breast cancer $[105,106]$. A similar phenotype has been reproduced with the overexpression of the downstream component $\beta$-Catenin in transgenic mice $[105,106]$. Moreover, mice that overexpress Wnt-1 or an active form of $\beta$-catenin present an expansion of undifferentiated precursors in the SP [22], and the size of this SP correlate with the risk of tumor development [112] indicating a direct implication of Wnt pathway in mammary stem cell self-renewal.

\section{Notch Pathway}

Notch pathway has been also related with mammary stem cell self-renewal. In particular, some members of Notch pathway, like Notch-4, seem to participate in normal mammary gland development, and the overexpression of Notch-4 in vitro promotes branching morphogenesis and blocks the differentiation of normal breast epithelial cells [113]. Moreover, transgenic mice that overexpress Notch-4 also develop dysplasias and breast tumors [114-116]. Notch family has also been implicated in breast cancer, for example, Notch-4 is up-regulated in different human breast cancer cell lines [117] and Notch-1 can transform normal breast epithelial cells of some mice like HC11 [118]. But the role of Notch family in breast cancer seems to be dual; the overexpression of Notch-1 in tumors has been related with poor prognosis, and Notch-2 overexpression has been related with good prognosis [119]. The use of in vitro assays is helping to dissect the complex role of Notch pathway in breast physiology and pathology. The stimulation or inhibition of this pathway, in particular Notch-4, in non-adherent in vitro mammospheres demonstrated that this pathway not only promotes self-renewal in stem cells, but also the proliferation in early progenitors. Interestingly, this pathway also exerts its action in cell fate 
determination, facilitating the commitment to the myoepithelial lineage and preventing terminal differentiation [42].

\section{Hedgehog Pathway}

Hedgehog signaling has been also implicated in the maintenance of both stem and progenitor cells of the mammary gland. There are indirect evidences that suggest the implication of Hedgehog signaling in stem cell self-renewal of the mammary tissue. Firstly, Hedgehog pathway has been implicated in breast embryonic development and adult tissue remodeling, and the disruption of Ptc-1 receptor or Gli-2 transcription factor generate ductal dysplasias in transgenic mice [120, 121]. Secondly, Hedgehog signaling has also been related with breast cancer development; for example, it has been described that the importance of certain polymorphisms of Ptc- 1 in the risk of breast cancer is associated with the use of oral contraceptive hormones [122], and the existence of Ptc1 mutations in breast cancer [123]. On the other hand, cyclopamine, a potent hedgehog pathway inhibitor, inhibit the growth of breast cancer cell lines in vitro.

Others pathways that have been implicated in mammary stem cell self-renewal are: ER $\alpha$ [54]; TGF $\beta$ [124, 125], LIF [126], Prl/GH [32] and EGF [32]. It is not wellunderstood how these pathways interact in a global scenario to regulate self-renewal capability in stem cells. It is interesting to note that deregulation of Wnt, Notch or Hedgehog signaling pathways originate alterations in self-renewal activity and, at the same time, in the differentiation program. In many cases the block in the differentiation precludes cancer development, an association that has also been well-established in hematopoietic malignancies. This similitude could indicate a common mechanism for cancer development in tumors from both epithelial and mesenchymal origin.

\section{FUTURE PERSPECTIVES}

The existence of cancer stem cells has important consequences in the breast cancer field and, in particular, in cancer prevention and therapy. Since it seems that the oncogenic events that initiate breast cancer occurs in stem cells early in life [12], it would be very 
important to identify those agents responsible for breast cancer initiation. In this sense, epidemiological studies comparing breast cancer development in countries with low and high incidence of the disease, and migratory movements offer a unique scenario to study the environmental effect on breast cancer development and would be essential in breast cancer prevention [127].

Another important issue would be to entirely understand the process that leads to the protective effect of pregnancy in breast cancer development. There are still a number of questions to be answered; for example it is not clear why the first pregnancy exerts the protective effect only early in life or, in other words, why a pregnancy later in life is not so efficient to eliminate those putative stem cells susceptible to be initiated. In any case, this interesting hypothesis offers a rationale for breast cancer prevention. Exciting studies have been carried out already in rodents [88-99] but it is controversial if this approach could have any benefit in women with high susceptibility to breast cancer, like in Brca1deficient patients [128]; indeed, the same lack of protection has been demonstrated in P53 deficient mice [129]. In any case, it could be possible that most women with sporadic forms of breast cancer could be benefited from similar strategies of prevention.

The possibility that cancers arise and are maintained from a small population with stem cell capacity indicates that components of the self-renewal and asymmetric division pathways could be the targets for more effective therapies. One possibility for cancer therapy would be to develop methods to encourage stem cells to disrupt their asymmetric division and leave their undifferentiated self-renewing state entering in tissue specific differentiation programmes. Several examples already exist in which differentiation inducing agents, such us retinoid acid or PPAR- $\gamma$ agonists, have been used for the treatment of M3 acute myeloid leukemia and myxoid liposarcoma, respectively [130, 131]. Although normal stem cells function probably relies on very similar if not the same molecular mechanisms, it will be a challenge to develop therapies that discriminate between normal and cancer stem cells, but there is no doubt that switching off the stem cell self-renewal program is an exciting possibility for cancer therapy. 


\section{ACKNOWLEDGEMENTS}

We apologize to many of our colleagues whose original work could not be cited due to space constrains.

J.P.L. is an investigator of the "Programa Ramón y Cajal” from the Ministerio Español de Ciencia y Tecnología, and is associated to the Departamento de Medicina, Universidad de Salamanca; his work is supported by the "Samuel Solorzano Foundation" and by a grant from the "Fondo de Investigación Sanitaria (FIS), Instituto de Salud Carlos III". R.G.S. work is supported by a grant from the "Fundación de Investigación Médica Mutua Madrileña Automovilista”.

\section{REFERENCES}

[1] Lajtha LG, Gilbert CW. In Cellular Radiation Biology 118-154. (Williams and Wilkins. Baltimore, Maryland, USA, 1965).

[2] Kordon EC, and Smith GH. An entire functional mammary gland may comprise the progeny from a single cell. Development 1998; 125: 1921-30.

[3] Shackleton M, Vaillant F, Simpson KJ, et al. Generation of a functional mammary gland from a single stem cell. Nature. 2006; 439: 84-8.

[4] Stingl J, Eirew P, Ricketson I, et al. Purification and unique properties of mammary epithelial stem cells. Nature. 2006; 439: 993-7.

[5] Reya T, Morrison SJ, Clarke MF, Weissman IL. Stem cells, cancer, and cancer stem cells. Nature 2001; 414: 105-11.

[6] Perez-Losada J, Balmain A. Stem-cell hierarchy in skin cancer. Nat Rev Cancer. 2003; 3: 434-43.

[7] Hennighausen L, Robinson GW. Signaling pathways in mammary gland development. Dev Cell. 2001; 1: 467-75. 
[8] DeOme KB, Fauklin LJ Jr, Bern HA, Blair PB. Development of mammary tumors from hyperplastic alveolar nodules transplanted into gland-free mammary fat pads of female C3H mice. Cancer Res. 1959; 19: 515-20.

[9] Pierce GB. Neoplasms, differentiation, mutations. Am J Pathol 1974, 77: 103-118.

[10] Pierce GB. Neoplastic stem cells. Adv Pathobiol. 1977; 6: 141-52.

[11] Pierce GB, Nakane PK, Martinez-Hernandez A, Ward JM. Ultrastructural comparison of differentiation of stem cells of murine adenocarcinomas of colon and breast with their normal counterparts. J Natl Cancer Inst. 1977; 58: 1329-45.

[12]Tokunaga M, Norman JE Jr, Asano M, et al. Malignant breast tumors among atomic bomb survivors, Hiroshima and Nagasaki,1950-74. J Natl Cancer Inst. 1979; 62: 1347-59.

[13] Aisenberg AC, Finkelstein DM, Doppke KP, Koerner FC, Boivin JF, Willett CG. High risk of breast carcinoma after irradiation of young women with Hodgkin's disease. Cancer. 1997; 79: 1203-10.

[14] Chang CC, Sun W, Cruz A, Saitoh M, Tai MH, Trosko JE. A human breast epithelial cell type with stem cell characteristics as target cells for carcinogenesis. Radiat Res 2001; 155: 201-7.

[15] Smith GH. Mammary cancer and epithelial stem cells: a problem or a solution? Breast Cancer Res 2002; 4: 47-50.

[16] Smalley M, Ashworth A. Stem cells and breast cancer: a field in transit. Nature Rev Cancer 2003; 3: 832-44.

[17] Dontu G, Al-Hajj M, Abdallah WM, Clarke MF, Wicha MS. Stem cells in normal breast development and breast cancer. Cell Prolif 2003; 36: 59-72.

[18] Waterworth A. Introducing the concept of breast cancer stem cells. Breast Cancer Res 2004; 6: 53-54.

[19] Li Y, Rosen JM. Stem/progenitor cells in mouse mammary gland development and breast cancer. J Mammary Gland Biol Neoplasia 2005; 10: 17-24.

[20] Tsai YC, Lu Y, Nichols PW, Zlotnikov G, Jones PA, Smith HS. Contiguous patches of normal human mammary epithelium derived from a single stem cell: implications for breast carcinogenesis. Cancer Res 1996; 56: 402-04. 
[21] Going JJ, Abd El-Monem HM, Craft JA. Clonal origins of human breast cancer. J Pathol 2001; 194: 406-12.

[22] Li Y, Welm B, Podsypanina K, et al. Evidence that transgenes encoding components of the Wnt signaling pathway preferentially induce mammary cancers from progenitor cells. Proc Natl Acad Sci U S A 2003; 100: 15853-58.

[23] Kenney NJ, Smith GH, Lawrence E, Barrett JC, Salomon DS. Identification of stem cell units in the terminal end bud and duct of the mouse mammary gland. J Biomed Biotechnol 2001; 1: 133-43.

[24] Welm BE, Tepera SB, Venezia T, Graubert TA, Rosen JM, Goodell MA. Sca1 (pos) cells in the mouse mammary gland represent an enriched progenitor cell population. Dev Biol 2002; 245: 42-56.

[25] Smith GH. Label-retaining epithelial cells in mouse mammary gland divide asymmetrically and retain their template DNA strands. Development 2005; 132: 681-87.

[26] Clarke RB, Spence K, Anderson E, Howell A, Okano H, Potten CS. A putative human breast stem cell population is enriched for steroid receptor-positive cells. Dev Biol 2005; 277: 443-56.

[27] Hirschmann-Jax C, Foster AE, Wulf GG, et al. A distinct "side population" of cells with high drug efflux capacity in human tumor cells. Proc Natl Acad Sci U S A 2004; 101: 14228-33.

[28] Goodell MA, McKinney-Freeman S, Camargo FD. Isolation and characterization of side population cells. Methods Mol Biol 2005; 290: 343-52.

[29] Alvi AJ, Clayton H, Joshi C, et al. Functional and molecular characterisation of mammary side population cells. Breast Cancer Res 2003; 5: R1-R8.

[30] Smalley MJ, Clarke RB. The mammary gland "side population': a putative stem/progenitor cell marker? J Mammary Gland Biol Neoplasia 2005; 10: 37-47.

[31] Welm B, Behbod F, Goodell MA, Rosen JM. Isolation and characterization of functional mammary gland stem cells. Cell Prolif 2003; 36: 17-32.

[32] Dontu G, Abdallah WM, Foley JM, et al. In vitro propagation and transcriptional profiling of human mammary stem/progenitor cells. Genes Dev 2003; 17: 1253-1270.

[33] Clarke RB, Anderson E, Howell A, Potten CS. Regulation of human breast epithelial stem cells. Cell Prolif 2003; 36: 45-58. 
[34] Clayton H, Titley I, Vivanco M. Growth and differentiation of progenitor/stem cells derived from the human mammary gland. Exp Cell Res 2004; 297: 444-60.

[35] Stingl J, Eaves CJ, Kuusk U, Emerman JT. Phenotypic and functional characterization in vitro of a multipotent epithelial cell present in the normal adult human breast. Differentiation 1998; 63: 201-13.

[36] Stingl J, Eaves CJ, Zandieh I, Emerman JT. Characterization of bipotent mammary epithelial progenitor cells in normal adult human breast tissue. Breast Cancer Res Treat 2001; 67: 93-109.

[37] Gudjonsson T, Villadsen R, Nielsen HL, Ronnov-Jessen L, Bissell MJ, Petersen OW. Isolation, immortalization, and characterization of a human breast epithelial cell line with stem cell properties. Genes Dev 2002; 16: 693-706.

[38] Bocker W, Moll R, Poremba C, et al. Common adult stem cells in the human breast give rise to glandular and myoepithelial cell lineages: a new cell biological concept. Lab Invest 2002; 82: 737-46.

[39] Dontu G, Wicha MS. Survival of mammary stem cells in suspension culture: implications for stem cell biology and neoplasia. J Mammary Gland Biol Neoplasia 2005; 10: 75-86.

[40] Campos LS. Neurospheres: insights into neural stem cell biology. J Neurosci Res 2004; 78: 761-69.

[41] Suzuki H, Taguchi T, Tanaka H, et al. Neurospheres induced from bone marrow stromal cells are multipotent for differentiation into neuron, astrocyte, and oligodendrocyte phenotypes. Biochem Biophys Res Commun 2004; 322: 918-22.

[42] Dontu G, Jackson KW, McNicholas E, Kawamura MJ, Abdallah WM, Wicha MS. Role of Notch signaling in cell-fate determination of human mammary stem/progenitor cells. Breast Cancer Res 2004; 6: 605-615.

[43] Rudland PS. Histochemical organization and cellular composition of ductal buds in developing human breast: evidence of cytochemical intermediates between epithelial and myoepithelial cells . J. Histochem Cytochem 1991; 39: 1471-84 .

[44] Sapino A, Macri L, Gugliotta P, et al. Immunophenotypic properties and estrogen dependency of budding cell structures in the developing mouse mammary gland. Differentiation 1993; 55: 13-8 . 
[45] Li P, Barraclough R , Fernig DG , Smith JA , Rudland PS. Stem cells in breast epithelia . Int J Exp Pathol 1998 ; 79 : 193-206.

[46] Cardiff RD, Wellings SR . The comparative pathology of human and mouse mammary glands. J Mammary Gland Biol Neoplasia 1999; 4: 105-22 .

[47] Smith GH, Medina D. A morphologically distinct candidate for an epithelial stem cell in mouse mammary gland. J Cell Sci 1988; 90: 173-83 .

[48] Daniel CW, Young LJ, Medina D, Deome KB. The influence of mammogenic hormones on serially transplanted mouse mammary gland. Exp Gerontol 1971; 6: 95-101.

[49] Chepko G, Smith GH. Three division-competent, structurally-distinct cell populations contribute to murine mammary epithelial renewal. Tissue Cell 1997; 29: 23953 .

[50] Smith CA, Monaghan P, Neville AM. Basal clear cells of the normal human breast. Virchows Arch A Pathol Anat Histopathol 1984; 402: 319-29.

[51] Kao CY, Nomata K, Oakley CS, Welsch CW, Chang CC. Two types of normal human breast epithelial cells derived from reduction mammoplasty: phenotypic characterization and response to SV40 transfection. Carcinogenesis 1995; 16: 531-8.

[52] Nagle RB, Bocker W, Davis JR, et al. Characterization of breast carcinomas by two monoclonal antibodies distinguishing myoepithelial from luminal epithelial cells. $\mathrm{J}$ Histochem Cytochem 1986; 34: 869- 81.

[53] Villadsen R, Fridriksdottir AJ, Ronnov-Jessen L, et al. Evidence for a stem cell hierarchy in the adult human breast. J Cell Biol 2007; 177: 87-101.

[54] Dontu G, El-Ashry D, Wicha MS. Breast cancer, stem/progenitor cells and the estrogen receptor. Trends Endocrinol Metab 2004; 15: 193-7.

[55] Kouros-Mehr H, Slorach EM, Sternlicht MD, Werb Z. GATA-3 maintains the differentiation of the luminal cell fate in the mammary gland. Cell 2006;127:1041-55.

[56] Asselin-Labat ML, Sutherland KD, Barker H, et al. Gata-3 is an essential regulator of mammary-gland morphogenesis and luminal-cell differentiation. Nat Cell Biol 2007; 9: 201-9.

[57] Dvorak HF. Tumors: wounds that do not heal. Similarities between tumor stroma generation and wound healing. N Engl J Med 1986; 315: 1650-9. 
[58] Hamburger AW, Salmon SE. Primary bioassay of human tumor stem cells. Science 1977; 197: 461-3.

[59] Bonnet D, Dick JE. Human acute myeloid leukemia is organized as a hierarchy that originates from aprimitive hematopoietic cell. Nat Med 1997; 3: 730-7.

[60] Cobaleda C, Gutierrez-Cianca N, Perez-Losada J, et al. A primitive hematopoietic cell is the target for the leukemic transformation in human Philadelphiapositive acute lymphoblastic leukemia.Blood 2000; 95: 1007-13.

[61] Perez-Losada J, Gutierrez-Cianca N, Sanchez-Garcia I. Philadelphia-positive Bcell acute lymphoblastic leukemia is initiated in an uncommitted progenitor cell. Leuk Lymphoma 2001; 42: 569-76.

[62] Singh SK, Hawkins C, Clarke ID, et al. Identification of human brain tumour initiating cells. Nature 2004; 432: 396-401.

[63] Al-Hajj M, Wicha MS, Benito-Hernandez A, Morrison SJ, Clarke MF. Prospective identification of tumorigenic breast cancer cells. Proc Natl Acad Sci U S A. 2003; 100: 3983-8.

[64] Ponti D, Costa A, Zaffaroni N, et al. Isolation and in vitro propagation of tumorigenic breast cancer cells with stem/progenitor cell properties. Cancer Res 2005; 65: 5506-11.

[65] Jamieson CH, Ailles LE, Dylla SJ, et al. Granulocyte-macrophage progenitors as candidate leukemic stem cells in blast-crisis CML. N Engl J Med 2004; 351: 657-67.

[66] Krivtsov AV, Twomey D, Feng Z, et al. Transformation from committed progenitor to leukaemia stem cell initiated by MLL-AF9. Nature 2006; 442: 818-22.

[67] Cobaleda C, Jochum W, Busslinger M. Conversion of mature B cells into T cells by dedifferentiation to uncommitted progenitors. Nature 2007; 449: 473-7.

[68] Vargo-Gogola T, Rosen JM. Modelling breast cancer: one size does not fit all. Nat Rev Cancer. 2007; 7: 659-72.

[69] Fidler IJ. The biology of cancer metastasis or, 'you cannot fix it if you do not know how it works'. Bioessays. 1991; 13: 551-4.

[70] Blau HM, Brazelton TR, Weimann JM. The evolving concept of a stem cell: entity or function? Cell 2001;105: 829-41. 
[71] Lowenberg B, Sonneveld P. Resistance to chemotherapy in acute leukemia. Curr Opin Oncol. 1998; 10: 31-5.

[72] Gottesman MM, Fojo T, Bates SE. Multidrug resistance in cancer: role of ATPdependent transporters. Nat Rev Cancer. 2002; 2: 48-58.

[73] Dean M, Fojo T, Bates S. Tumour stem cells and drug resistance. Nat Rev Cancer. 2005;5: 275-84.

[74] Donnenberg VS, Donnenberg AD. Multiple drug resistance in cancer revisited: the cancer stem cell hypothesis. J Clin Pharmacol 2005; 45: 872-7.

[75] Naumov GN, MacDonald IC, Chambers AF, Groom AC. Solitary cancer cells as a possible source of tumour dormancy? Semin Cancer Biol 2001; 11: 271-6.

[76] Woodruff M. The Walter Hubert Lecture, 1982. Interaction of cancer and host. Br J Cancer. 1982; 46:313-22.

[77] Callaway MP, Briggs JC. The incidence of late recurrence [greater than 10 years]; an analysis of 536 consecutive cases of cutaneous melanoma. Br J Plast Surg 1989; 42:46-9.

[78] van Rhee F, Lin F, Cross NC, et al. Detection of residual leukaemia more than 10 years after allogeneic bone marrow transplantation for chronic myelogenous leukaemia. Bone Marrow Transplant 1994; 14: 609-12.

[79] Yong AS, Goldman JM Relapse of chronic myeloid leukaemia 14 years after allogeneic bone marrow transplantation. Bone Marrow Transplant 1999; 23: 827-8.

[80] Holyoake TL, Jiang X, Jorgensen HG, et al. Primitive quiescent leukemic cells from patients with chronic myeloid leukemia spontaneously initiate factor-independent growth in vitro in association with up-regulation of expression of interleukin-3. Blood 2001; 97: 720-8.

[81] Schirrmacher V. T-cell immunity in the induction and maintenance of a tumour dormant state. Semin Cancer Biol 2001; 11: 285-95.

[82] Naumov GN, Akslen LA, Folkman J. Role of angiogenesis in human tumor dormancy: animal models of the angiogenic switch Cell Cycle 2006; 5: 1779-87.

[83] Dux A, Muhlbock O. Decreased susceptibility to the mammary tumour agent in mice with advancing age. Int J Cancer 1966; 1: 409-17. 
[84] Russo J, Tay LK, Russo IH. Differentiation of the mammary gland and susceptibility to carcinogenesis. Breast Cancer Res Treat 1982; 2: 5-73.

[85] Kolonel LN, Altshuler D, Henderson BE.The multiethnic cohort study: exploring genes, lifestyle and cancer risk. Nat Rev Cancer 2004; 4: 519-27.

[86] Kelsey JL, Gammon MD, John EM. Reproductive factors and breast cancer. Epidemiol Rev. 1993; 15: 36-47.

[87] Lambe M, Hsieh CC, Chan HW, Ekbom A, Trichopoulos D, Adami HO. Parity, age at first and last birth, and risk of breast cancer: a population-based study in Sweden. Breast Cancer Res Treat 1996; 38: 305-11.

[88] Russo J, Russo IH. Influence of differentiation and cell kinetics on the susceptibility of the rat mammary gland to carcinogenesis. Cancer Res 1980; 40: 267787.

[89] Moon RC, Pike MC, Siiteri PK, Welsch CW, Eds. Influence of pregnancy and lactation on experimental mammary carcinogenesis. In Banbury Report 8 Hormones and Breast Cancer. Cold Spring Harbor, NY: Cold Spring Harbor Laboratory 1981; 353-61.

[90] Welsch CW: Host factors affecting the growth of carcinogen-induced rat mammary carcinomas: a review and tribute to Charles Brenton Huggins. Cancer Res 1985; 45: 3415-43.

[91] Sinha DK, Pazik JE, Dao TL. Prevention of mammary carcinogenesis in rats by pregnancy: effect of full-term and interrupted pregnancy. Br J Cancer 1988; 57: 390-4.

[92] Russo IH, Russo J. Mammary gland neoplasia in long-term rodent studies. Environ Health Perspect 1996; 104: 938-967.

[93] Swanson SM, Whitaker LM, Stockard CR, et al. Hormone levels and mammary epithelial cell proliferation in rats treated with a regimen of estradiol and progesterone that mimics the preventive effect of pregnancy against mammary cancer. Anti-cancer Res 1997; 17: 4639-45.

[94] Yang J, Yoshizawa K, Nandi S, Tsubura A. Protective effects of pregnancy and lactation against $\mathrm{N}$-methyl-N-nitrosourea-induced mammary carcinomas in female Lewis rats. Carcinogenesis 1999; 20: 623-8. 
[95] Rajkumar L, Guzman RC, Yang J, Thordarson G, Talamantes F, Nandi S. Shortterm exposure to pregnancy levels of estrogen prevents mammary carcinogenesis. Proc Natl Acad Sci USA 2001; 98: 11755-59.

[96] Rajkumar L, Kittrell FS, Guzman RC, Brown PH, Nandi S, Medina D. Hormone-induced protection of mammary tumorigenesis in genetically engineered mouse models. Breast Cancer Res 2007; 9: R12.

[97] Medina D. Breast cancer: the protective effect of pregnancy. Clin Cancer Res. 2004; 10: 380-4.

[98] Blakely CM, Stoddard AJ, Belka GK, et al. Hormone-induced protection against mammary tumorigenesis is conserved in multiple rat strains and identifies a core gene expression signature induced by pregnancy. Cancer Res. 2006; 66: 6421-31.

[99] Blakely CM, Sintasath L, D'Cruz CM, et al. Developmental stage determines the effects of MYC in the mammary epithelium. Development 2005; 132: 1147-60.

[100] Russo J, Moral R, Balogh GA, Mailo D, Russo IH. The protective role of pregnancy in breast cancer. Breast Cancer Res 2005; 7: 131-42.

[101] Russo J, Balogh GA, Heulings R, et al. Molecular basis of pregnancy-induced breast cancer protection. Eur J Cancer Prev. 2006; 15: 306-42.

[102] Russo J, Balogh GA, Chen J, et al The concept of stem cell in the mammary gland and its implication in morphogenesis, cancer and prevention. Front Biosci. 2006; 11: $151-72$.

[103] D'Cruz CM, Moody SE, Master SR, et al. Persistent parity-induced changes in growth factors, TGF-beta3, and differentiation in the rodent mammary gland. Mol Endocrinol 2002; 16: 2034-51.

[104] Balogh GA, Heulings R, Mailo DA, et al. Genomic signature induced by pregnancy in the human breast. Int J Oncol 2006; 28: 399-410.

[105] Brennan KR, Brown AM. Wnt proteins in mammary development and cancer. J Mammary Gland Biol Neoplasia 2004; 9: 119-31.

[106] Reya T, Clevers H. Wnt signalling in stem cells and cancer. Nature 2005; 434: 843-50. 
[107] Brisken C, Heineman A, Chavarria T, et al. Essential function of Wnt-4 in mammary gland development downstream of progesterone signaling. Genes Dev 2000; 14: 650-4.

[108] Lin SY, Xia W, Wang JC, et al. Beta-catenin, a novel prognostic marker for breast cancer: its roles in cyclin D1 expression and cancer progression. Proc Natl Acad Sci U S A 2000; 97: 4262-66.

[109] Milovanovic T, Planutis K, Nguyen A, et al. Expression of Wnt genes and frizzled 1 and 2 receptors in normal breast epithelium and infiltrating breast carcinoma. Int J Oncol 2004; 25: 1337-42.

[110] Watanabe O, Imamura H, Shimizu T, et al. Expression of twist and wnt in human breast cancer. Anticancer Res 2004; 24: 3851-56.

[111] Jonsson M, Dejmek J, Bendahl PO, Andersson T. Loss of Wnt-5a protein is associated with early relapse in invasive ductal breast carcinomas. Cancer Res 2002; 62: 409-16.

[112] Liu BY, McDermott SP, Khwaja SS, Alexander CM. The transforming activity of Wnt effectors correlates with their ability to induce the accumulation of mammary progenitor cells. Proc Natl Acad Sci U S A 2004; 101: 4158-63.

[113] Uyttendaele H, Soriano JV, Montesano R, Kitajewski J. Notch4 and Wnt-1 proteins function to regulate branching morphogenesis of mammary epithelial cells in an opposing fashion. Dev Biol 1998; 196: 204-17.

[114] Gallahan D, Jhappan C, Robinson G, et al. Expression of a truncated Int3 gene in developing secretory mammary epithelium specifically retards lobular differentiation resulting in tumorigenesis. Cancer Res 1996; 56: 1775-85.

[115] Jhappan C, Gallahan D, Stahle C, et al. Expression of an activated Notchrelated int-3 transgene interferes with cell differentiation and induces neoplastic transformation in mammary and salivary glands. Genes Dev 1992; 6: 345-55.

[116] Smith GH, Gallahan D, Diella F, Jhappan C, Merlino G, Callahan R. Constitutive expression of a truncated INT3 gene in mouse mammary epithelium impairs differentiation and functional development. Cell Growth Differ 1995; 6: 563-77. 
[117] Imatani A, Callahan R. Identification of a novel NOTCH-4/INT-3 RNA species encoding an activated gene product in certain human tumor cell lines. Oncogene 2000; 19: 223-31.

[118] Dievart A, Beaulieu N, Jolicoeur P. Involvement of Notch1 in the development of mouse mammary tumors. Oncogene 1999; 18: 5973-81.

[119] Clarke RB. Human breast cell proliferation and its relationship to steroid receptor expression. Climacteric 2004; 7: 129-37.

[120] Lewis MT, Ross S, Strickland PA, et al. Defects in mouse mammary gland development caused by conditional haploinsufficiency of Patched-1. Development 1999; 126: 5181-93.

[121] Lewis MT, Ross S, Strickland PA, et al. The Gli2 transcription factor is required for normal mouse mammary gland development. Dev Biol 2001; 238: 133-44.

[122] Chang-Claude J, Dunning A, Schnitzbauer U, et al. The patched polymorphism Pro1315Leu [C3944T] may modulate the association between use of oral contraceptives and breast cancer risk. Int J Cancer 2003; 103: 779-83.

[123] Xie J, Johnson RL, Zhang X, et al. Mutations of the PATCHED gene in several types of sporadic extracutaneous tumors. Cancer Res 1997; 57: 2369-72.

[124] Ewan KB, Oketch-Rabah HA, Ravani SA, Shyamala G, Moses HL, BarcellosHoff MH. Proliferation of estrogen receptor-alpha-positive mammary epithelial cells is restrained by transforming growth factor-beta1 in adult mice. Am J Pathol 2005; 167: 409-17.

[125] Boulanger CA, Wagner KU, Smith GH. Parity-induced mouse mammary epithelial cells are pluripotent, self-renewing and sensitive to TGF-beta1 expression. Oncogene 2005; 24: 552-60.

[126] Kritikou EA, Sharkey A, Abell K, et al. A dual, non-redundant, role for LIF as a regulator of development and STAT3-mediated cell death in mammary gland. Development 2003; 130: 3459-68.

[127] Kolonel LN, Altshuler D, Henderson BE. The multiethnic cohort study: exploring genes, lifestyle and cancer risk. Nat Rev Cancer. 2004; 4:519-27.

[128] Medina D, Kittrell FS. p53 function is required for hormone-mediated protection of mouse mammary tumorigenesis. Cancer Res 2003; 63: 6140-3. 
[129] Kotsopoulos J, Lubinski J, Lynch HT, et al. Age at first birth and the risk of breast cancer in BRCA1 and BRCA2 mutation carriers. Breast Cancer Res Treat 2007; 105: 221-28.

[130] Bruserud O, Gjertsen BT. New strategies for the treatment of acute myelogenous leukemia: differentiation induction--present use and future possibilities. Stem Cells 2000; 18: 157-65.

[131] Demetri GD, Fletcher CD, Mueller E, et al. Induction of solid tumor differentiation by the peroxisome proliferator-activated receptor-gamma ligand troglitazone in patients with liposarcoma. Proc Natl Acad Sci U S A. 1999; 96: 3951-6. 


\section{Figure legends}

Fig. (1). Mammary stem cell hierarchy and breast cancer phenotype. (A) Simplified model of epithelial cell hierarchy in the mammary gland: LTSC-MRU (Long-Term Stem Cell Mammary Regenerating Unit), STSC-MRU (Short-Term Stem Cell Mammary Regenerating Unit). (B and C) Proposed models to explain breast cancer ontology: (B) The final phenotype of each breast cancer subtype would reflect the phenotype of the lineage of the initiating cell. (C) In the second model, all breast tumor subtypes would have the origin in the same primitive pool of mammary stem cells, which would initiate a differentiation program driven by the molecular pathways activated by the oncogenic events. 
Fig. (2). Clinical implications of breast cancer stem cell hypothesis. (A) Stem cells (SC) are the only subpopulation with self-renewal capability and are responsible for tissue maintenance, most part of them are quiescent in G0. (B) After an oncogenic mutation SC can be initiated, these initiated cells also can be dormant in G0 for long periods of time. (C) After promotion stimuli these initiated cells divide and acquire secondary mutations and eventually are transformed in cancer stem cells (CSCs), which, as their normal counterparts, can be in G0 for a long period of time. (D) CSCs generate and maintain the tumor tissue, and (E) can metastasize and originate long distant tumors. (F) After the treatment with standard therapies, most part of tumoral cells are eliminated, (G) but cancer stem cells, that are mostly quiescent in G0, are resistant to quimiotherapy and lead to tumor relapse after months or even years of the initial treatment. 


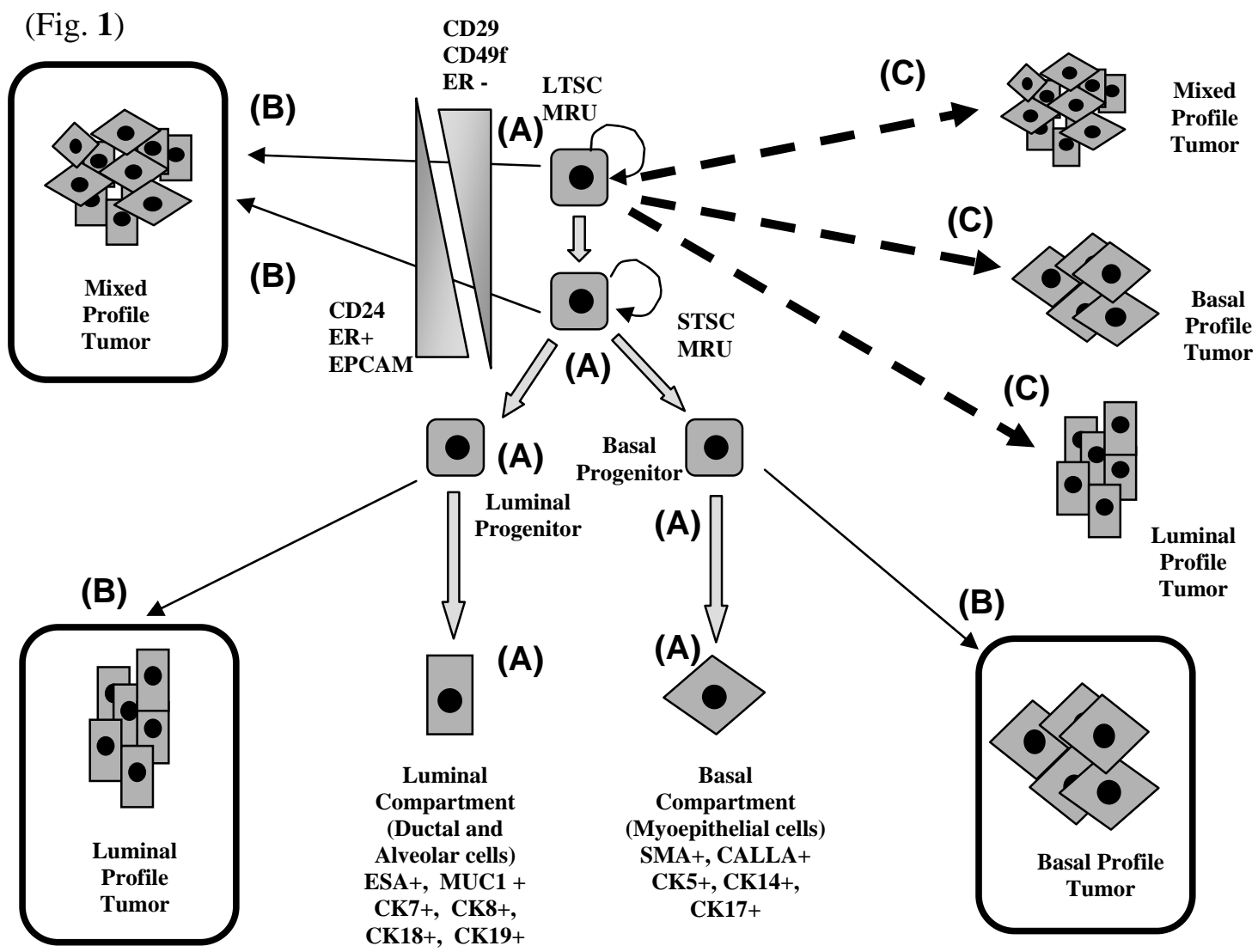


(Fig. 2)

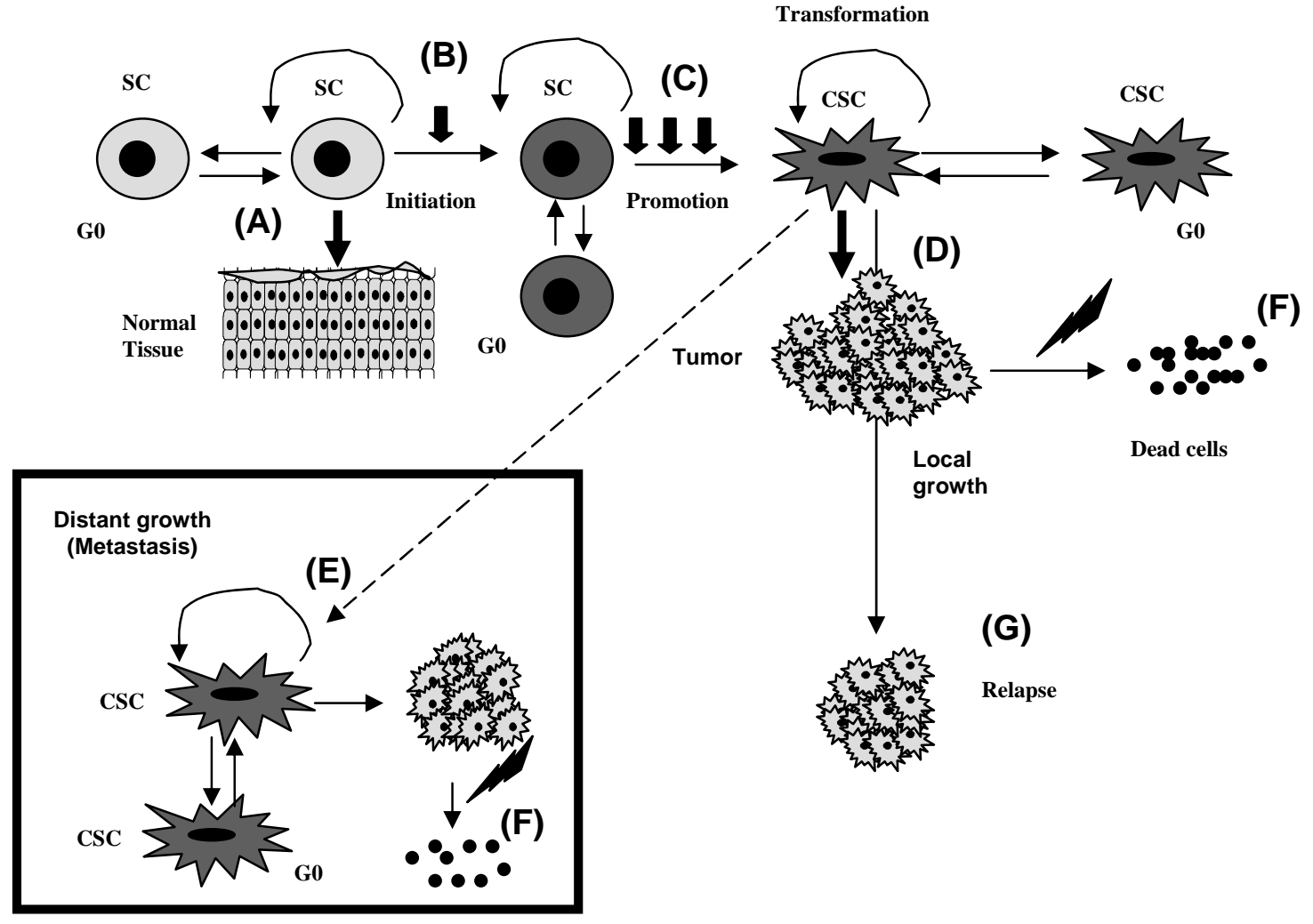

